\title{
A corpus-assisted study of the discourse marker 'well' as an indicator of judges' institutional roles in court cases with litigants in person
}

\begin{abstract}
The article concentrates on court cases with litigants in person (lay people who act on their own behalf in legal proceedings without a counsel or solicitor) and discusses the challenges of building a corpus of courtroom discourse where it is crucial to distinguish between speakers due to their distinct institutional roles. The corpus incorporates seven sub-corpora of verbatim transcripts from different court cases with litigants in person and comprises over 11 million tokens. The focus of the article is on the interplay between the legal and lay discourse types and how judges project their institutional roles through 'well'-initiated turns directed at litigants in person and counsels. As a versatile discourse marker, 'well' provides a good opportunity to explore how judges have to adapt their roles to ensure lay litigants in person receive the necessary support and that their lack of competence does not impede on the fairness of the proceedings. Given the breadth and importance of the topic of litigation in person, the article discusses how the tools and approaches of corpus linguistics can be helpful in this multi-disciplinary area where multiple functions and uses of individual linguistic features need to be explored in depth.
\end{abstract}

\section{Keywords}

Discourse markers, corpus linguistics, specialised corpora, institutional role of judges, litigants in person.

\section{Introduction}

Due to abrupt cuts in legal aid in England and Wales since July 2013 as a result of the Legal Aid, Sentencing and Punishment of Offenders Act 2012, civil courts are now struggling with the influx of lay people who act on their own behalf in legal proceedings without counsel or a solicitor (i.e. as litigants in person). The changes have an adverse impact on society as a whole as well as individuals, and raise serious concerns about the fairness of proceedings and access to justice. This is further complicated by the fact that research on the phenomenon of litigation in person is scarce and official reports (e.g. Report by the Judicial Working Group on Litigants in Person 2013) struggle to recognise the complex and multi-disciplinary character of the topic. Communication and interaction between the parties lies at the core of adversarial legal proceedings. The mere presence of litigants in person introduces many imbalances in power relations and affects the institutional roles of all participants involved, especially those of the judiciary.

The corpus discussed in this study was designed to bridge the gap between linguistic research on courtroom discourse and legal research on litigants in person. Real life communication is often overlooked in legal studies whereas linguistic studies may not have real impact for legal practitioners. This study attempts to bridge the gap by combining the analysis of i) authentic communication in court, and ii) the use of language for the strategic purposes of legal 
practitioners. For instance, corpus samples of interaction between judges and litigants in person can be used in the training of the judiciary on dealing with litigants in person at the Judicial College. The vision behind the corpus building was to meet the needs of both linguists and legal practitioners and create a tool for conducting multi-disciplinary research. Although the corpus at this stage has some limitations (see section 3), an analysis of the discourse marker 'well' shows that it can nevertheless illustrate different aspects of the interplay between legal and lay discourse types. The focus here is on the function of 'well' in its turn-initial position as used by judges in court proceedings with an unrepresented party.

Discourse markers in general and 'well' in particular are well-suited for indicating the participants' strategies of negotiating their institutional roles. Although discourse markers are semantically and grammatically optional and can be omitted without causing any deviations in meaning or irregularities in syntax (Fraser 1993: 6; Schourup 1998: 231), they play an important function in orienting the listeners and defining the force of the utterance (Norrick 2000; Hale 1999). Finding a unified definition for discourse markers is problematic since they do not form a unified group and differ significantly from their correlates (e.g. discourse marker 'like' v. its correlate verb 'like', discourse marker 'well' v. its correlate adverb 'well', discourse marker 'so' v. its correlate conjunction 'so'). Moreover, a single discourse marker can often be found to display a wide variety of uses and functions (Fraser 1993; Schourup 1998).

The core meaning of discourse markers (Fraser 1999) presents yet another puzzle for researchers because in pragmatic terms it is not always clear whether the meaning of the marker is intrinsic or influenced by the context (Cuenca 2008: 1373). What is important for this study, though, is that discourse markers are often indicative of power relationships as they help structure and control the interaction as well as negotiate the roles of speakers (Carter and McCarthy 2006: 212). Studies on the use of discourse markers in different social contexts and settings show that the role of speakers and their relationship influences the use and distribution of discourse markers (Carranza 2004; Fuller 2003). For instance, Fuller (2003) shows that in conversation the discourse marker 'well' is found to occur frequently in responses (i.e. second turn position), whereas in interviews it is used more often by the interviewer (i.e. first turn position).

The discourse marker 'well' is one of the most frequently studied discourse markers due to its versatile use and high occurrence in everyday conversation (Kim 2013; Jackson and Jones 2012; Lam 2010; Fuller 2003; Cuenca 2007; Schiffrin 1987; Svartvik 1980) as well as spoken interaction in institutional settings including interviews (Jackson and Jones 2012; Fuller 2003; Schiffrin 1987) and courtroom discourse (Innes 2010; Hale 1999). It has been studied as a turn-initial discourse marker occurring in all three positions: first pair part of adjacency pairs (Innes 2010; Hale 1999), second pair part (Innes 2010; Schiffrin 1987) and also third turn (Kim 2013).

In its textual function, the discourse marker 'well' introduces a change of topic (Fuller 2003), reinforces coherence links (Fuller 200; Schiffrin 1987; Lam 2010) or is used as a delay device when a speaker needs to pause (Cuenca 2008; Fuller 2003). The interpersonal 
functions of 'well' are mainly those of (i) a responsive marker, prefacing answers indicating insufficiency or incompleteness, or (ii) an emotive marker, conveying the speaker's surprise, dismissal or state of mind in general (Lam 2010). The interactional functions of the discourse marker 'well' range from (i) self-repair, self-correction and reformulation (Jackson and Jones 2013) to (ii) turn-management and taking the floor (Lam 2010). The discourse marker 'well' also holds an important pragmatic function, i.e. to initiate face threat mitigation (Jucker 1993; Fuller 2003; Innes 2010; Cuenca 2008). Given its wide range of textual, interpersonal, interactional, and pragmatic functions, turn initial 'well' provides scope for exploring how judges adapt their professional roles when dealing with litigants in person. Section 2 provides a more detailed reasoning of how the discourse marker 'well' in its different functions helps negotiate or establish institutional roles of the participants in courtroom settings, and section 5 illustrates different functions of 'well'-initiated turns as used by judges in courtroom proceedings with litigants in person.

\section{Previous research on the legal-lay discourse in courtroom settings and the role of discourse markers}

There is little research on communication challenges experienced by litigants in person, the judiciary, court staff or opposing counsels in court proceedings with an unrepresented party. Even the most recent publication on legal-lay discourse, an edited volume by Heffer et al (2013) Legal-lay communication: textual travels in the law, does not mention difficulties litigation in person brings to the judiciary and courts. Although the edited volume is a useful source of information on many communication issues arising from differences in legal and lay discourse types in a variety of contexts (e.g. police interviews, public hearings), the omission of self-representation as a topic shows an important gap in the research - a gap which this paper attempts to bridge.

Research dealing directly with linguistic aspects of litigation in person is limited to two short studies on small claims courts (O'Barr and Conley 1990; Conley and O'Barr 1998) and research conducted by the author (Tkačuková 2011, 2010, 2008, 2007). The first two studies concentrate on narrative structures and conclude that litigants in person use narrative devices common in everyday conversational interaction and therefore produce relational accounts instead of using narrative devices of rule-oriented accounts expected by the judiciary (e.g. self-represented litigants describe their feelings instead of limiting themselves to the facts). This is in line with Heffer's (2005: 20-24) observation of the tension between the paradigmatic (socio-scientific) mode of reasoning employed by legal professionals and the narrative mode of reasoning often used by lay participants (e.g. witnesses, jury members).

Similar to the findings of O'Barr and Conley (1990), single case studies conducted by the author (Tkačuková 2011, 2010, 2008, 2007) found that there is a disparity between the rules of everyday conversational discourse and pre-specified requirements of courtroom discourse. As a result, litigants in person, typically find it challenging to adapt their interactional habits and language use to the hostile atmosphere of cross-examination when it is necessary to 
discredit witnesses or their presentation of facts (Gibbons 2003). Professional counsels challenge witnesses by asking them closed leading questions and limiting their interactional space (Heffer 2005: ch.4; Luchjenbroers 1997; Philips 1987; Woodbury 1984; Harris 1984; Danet et al 1980) and coercing them into preferred replies by using controlling pragmatic strategies (Aldridge and Luchjenbroers 2007; Matoesian 2005; Gibbons 2003: 112 - 127; Cotterill 2003; Drew 1990; Conley and O'Barr 1998). Instead, the litigants in person in Tkačuková's data, based on the libel case McDonalds v Helen Steel ad David Morris, allowed too much interactional space for witnesses, used too many open questions and their closed questions were not restrictive enough (Tkačuková 2011, 2010). This is also reflected in their use of discourse markers. Hale (1999) notes that common discourse markers such as 'well' are used to signal coherence in everyday conversation, whereas in cross-examination the same discourse markers are used in their more challenging functions for indicating disagreement and controlling the flow of questioning. Tkačuková (2010) illustrates that discourse markers are used by litigants in person in their supportive function to indicate comprehension and acknowledgement during cross-examination instead of adding force to the challenging questioning. For the very fact that litigants in person were not always challenging enough, the judge had to interfere in their cross-examination and ask specifying questions.

The above-mentioned studies on litigants in person focus on the evidentiary stage of the proceedings (i.e. witness examination stages). The use and functions of discourse markers during the evidentiary stage have been analysed in several studies (Innes 2010; Hale 1999 Tkačuková 2010). In contrast, the focus of this article is on procedural stages (discussions between litigants in person, opposing counsels and judges about legal points and organisational matters). It is during procedural stages that most distinctions between legal and lay discourse types arise because judges need to ensure litigants in person are not disadvantaged due to their lack of legal training. The functions of discourse markers can thus indicate the roles of judges in cases with litigants in person.

The discourse marker 'well' in its initial position is especially well-placed for illustrating the interactional and communicative interplay between legal and lay participants. The reasons are numerous. Firstly, the discourse marker 'well' frequently occurs both in paradigmatic and narrative modes; it has a firmly established place in question/answer driven institutional settings such as court (Innes 2010) or interviews (Fuller 2003) as well as everyday conversation (Jackson and Jones 2013; Kim 2013; Fuller 2003; Schiffrin 1987; Svartvik 1980) or even storytelling (Norrick 2001).

Secondly, the discourse marker 'well' in its turn-initial position can help signal turn-taking management. Turn-taking in courtroom settings is strictly pre-specified with turn order and distribution of turns pre-allocated to speakers with specific roles (e.g. witnesses answer questions and are not permitted to offer any other types of contributions, counsel ask questions) and overlapping speech is avoided by counsel employing such remedial techniques as cut-offs or re-starts to restore the turn-taking order (Atkinson and Drew 1979: 67).

Litigants in person have, however, been found to follow turn-taking management common in everyday conversation, which is less orderly and lacks many pre-allocated aspects 
(Tkačuková 2010). They often interrupted witnesses or were interrupted by witnesses and their witness examination was thus disorderly (Tkačuková 2008). Judges were also found to interrupt witness examination conducted by litigant in person in order to ask witnesses additional questions or interfere with litigant in person's questioning strategies (Tkačuková 2010). In its function as a cohesive link between turns (Fuller 2003; Schiffrin 1987) and an initiator of self-repairs (Jackson and Jones 2013), 'well' is indicative of the turn-taking management during interaction between legal professionals and litigants in person.

There are two more functions of the discourse marker 'well' which often stand out in the interplay between the legal and lay discourse types and interaction styles: 'well' indicating inequalities in the institutional authority of the interlocutors, and 'well' as a mitigation device. In its first function the discourse marker 'well' controls the flow of the interaction (Carter and McCarthy 2006: 212) and adds force to coercive questioning or challenging replies (Innes 2010; Hale 1999). One of the judges' roles is to ensure litigants in person understand complicated legal concepts and principles related to their case. The orientation of the discourse marker 'well' backwards and forwards in specifying the meaning intended by the previous speaker and the current one (Schiffrin 1987) allows 'well'-initiated turns to unfold the negotiation of meaning happening between judges and litigants in person.

Furthermore, the function of 'well' as a mitigation device for toning down the potential face threat to the hearer (Innes 2010; Cuenca 2008; Fuller 2003; Jucker 1993) is especially important to legal scholars and practitioners. Due to the growing number of litigants in person, the traditional role of judges is currently undergoing change since judges increasingly have to undertake an additional role of being the main facilitator of the legal process and mitigator between the legal parties. Among other suggestions, the first official report by the Judicial Working Group on Litigants in Person (2013) advocates developing training for judges and court staff on dealing with litigants in person within the newly established Judicial College. The mitigating function of the discourse marker 'well' has a special place in the legal-lay discourse where litigants in person are in a disadvantaged position and can potentially find themselves in many face-threatening situations with judges and opposing counsel requiring action from them.

In general, linguistic research on the role of judges in legal proceedings with legal proceedings has been preoccupied by power inequalities, the difficulties of lay people with presenting their stories and the disparity between the paradigmatic and narrative modes in lay-legal discourse. Legal research on self-representation is more alert to potential complications litigants in person cause and the changing role of the judiciary. The discourse marker 'well' in all of its functions and versatile uses is in the ideal position to reflect all of the complexities of legal-lay interaction. Most importantly it has the potential to uncover mitigating strategies used by the judiciary and to show how judges negotiate the roles of litigants in person and the meaning of legal concepts.

\section{Data}


The corpus is based on verbatim transcripts from seven civil and criminal court cases transcribed by professional court transcribers. Civil cases are not generally audio recorded (with the exception of family cases, which are strictly confidential). Therefore the audio recordings were not available for the analysed cases. With the analysed criminal cases substantial effort was made to obtain recordings, but the recordings could not be released to researchers from abroad. It is extremely difficult to obtain even court transcripts due to a number of complications: the sensitive nature of the data and ethical considerations, the very high cost of transcription services, difficulties tracing case numbers of cases with litigants in person.

Furthermore, conducting linguistic analysis based on verbatim transcripts is not ideal for the purposes of spoken discourse analysis and the accuracy of verbatim court transcripts has been questioned in many studies due to the nature of spoken language and the fact that transcripts are produced for purely legal purposes (Fraser 2003; Eades 1996; Walker 1986). Sometimes transcribers make conscious changes in the participants' language. Reporter induced changes mostly include correction of inaccurate grammar, syntactic rearrangements or restoration of dialectal features into standard forms (Walker 1990: 228-232). The extent to which court reporters correct the speakers' language depends on the type of the participant they transcribe. The language of legal professionals and expert witnesses, for instance, is corrected more often as these professionals are expected to express themselves better than ordinary lay participants (Heffer 2005: 56; Walker 1990: 232-234). Even including punctuation in the transcription makes transcripts dependent on the stenographers' interpretation of an utterance (Fraser 2003; Eades 1996; Walker 1986). Interruptions are, for instance, usually indicated with dashes, but such a simplified system does not make it clear when exactly interruptions begin and for how long simultaneous speech lasts (Walker 1986: 211-213). However, these limitations are minimised by the fact that the current study concentrates on the formal features of interaction such as the use, function and occurrence of the discourse marker 'well'. In spite of the possibility of transcriber-induced correction, researchers consider court transcripts a valuable source for linguistic analysis (Eades 1996). From his observations in court, Heffer (2005: 58) concluded that in an overwhelming majority of cases the language presented in transcripts was accurate.

The corpus used in this research consists of 12,338,166 words and is a collection of seven sub-corpora, each based on a court case tried in different jurisdictions (England and Wales, USA and Canada). Table 1 shows the list of cases analysed, their types, jurisdictions and subcorpus size.

Table 1: List of sub-corpora outlining cases involving litigants in person (LiP)

\begin{tabular}{|l|l|l|c|}
\hline \multicolumn{1}{|c|}{ Case } & Case type & Country & Sub-corpus size \\
\hline $\begin{array}{l}\text { McDonald's Corporation v. } \\
\text { Helen Steel and David Morris } \\
\text { (McDonald's Sub-Corpus) }\end{array}$ & Libel & UK & $9,005,850$ tokens \\
\hline $\begin{array}{l}\text { David Irving v. Penguin } \\
\text { Books and Deborah Lipstadt }\end{array}$ & Libel & UK & $1,685,058$ tokens \\
\hline
\end{tabular}




\begin{tabular}{|l|l|l|l|}
\hline (Irving Sub-Corpus) & Civil & UK & 43,812 tokens \\
\hline $\begin{array}{l}\text { LiP v. an insurance company } \\
\text { Small Claims Sub-Corpus 1) }\end{array}$ & Criminal & USA & $1,384,469$ tokens \\
\hline $\begin{array}{l}\text { United States of America v. } \\
\text { James A. Traficant } \\
\text { (Traficant Sub-Corpus) }\end{array}$ & Civil & USA & 116,868 tokens \\
\hline $\begin{array}{l}\text { LiP v. a cable } \\
\text { communications company } \\
\text { (Small Claims Sub-Corpus 2) }\end{array}$ & Criminal & USA & 36,013 tokens \\
\hline $\begin{array}{l}\text { LiP v. family members } \\
\text { (Small Claims Sub-Corpus 3) }\end{array}$ & Civil & Canada & 66,096 tokens \\
\hline $\begin{array}{l}\text { LiP v. an investment company } \\
\text { (Small Claims Sub-Corpus 4) }\end{array}$ & Claims \\
\hline
\end{tabular}

In the corpus, there are three long and widely-publicised cases in which litigants in person chose to represent themselves despite having other options available: McDonald's Corporation v. Helen Steel and David Morris, David Irving v. Penguin Books and Deborah Lipstadt, United States of America v. James A. Traficant. The activists Steel and Morris chose to represent themselves after they were sued over the contents of the leaflets 'What's Wrong with McDonald's? Everything they don't Want you to Know', which they were distributing in public. David Irving, a British historian publicly claiming his sympathy for anti-Semitism, filed a libel suit against Penguin Books and Deborah Lipstadt for being labelled a Holocaust denier. James Traficant, a politician and member of the US House of Representatives, represented himself when federal corruption charges were brought against him. The other cases are small claims cases, for which there is no extra-linguistic information available and the names were anonymised.

Recent research conducted for the Ministry of Justice found that litigants in person coming from different educational, social and professional backgrounds, including those with high levels of education or professional experience, struggle with many aspects of the legal process (Trinder et al. 2014). Educational or professional background thus does not affect the individuals' capacity to represent themselves. For this reason the sub-corpora are comparable and relevant for the analysis of the discourse marker as used by judges in their communication with litigants in person.

The corpus is a work in progress which is being constantly supplemented with newly acquired verbatim transcripts. Each sub-corpus includes all stages of court cases, including evidentiary stages (witness examination), opening and closing statements and resolving procedural and organisational matters. Sub-corpora can be searched individually, in different combinations or as a whole corpus. Despite the differences in the size of individual subcorpora (caused by the duration of cases), jurisdictions, types of cases and types of litigants in person, the corpus as a whole presents a solid position for identifying specific problematic areas of court communication for litigants in person and the interplay between the legal and lay discourse types. 


\section{Corpus linguistic approach and corpus design}

A corpus approach offers several advantages for dealing with novel and timely topics: an easy way for incorporating new materials, re-usability for different types of analyses and the quick speed of processing data (McEnery et al. 2006). This is especially important for the interdisciplinary topic of self-representation, which is rapidly gaining in significance and impacts on a wide and varied community of legal professionals, stakeholders, policy makers and academics. A corpus approach allows researchers to extract individual lexical features from texts, quantify them and then put them into the wider context by identifying regular patterns and analysing the role of formal features for specific communicative purposes in the given context (Thornbury 2010: 276). The bottom-up approach provides an objective basis for the analysis and eliminates weaknesses that are sometimes associated with discourse or pragmatic analysis, such as subjective conclusions, selective extraction of features or decontextualised examples (McEnery and Wilson 2001: 115). The research into smaller specialised corpora shows that more contextualised corpora are better suited for exploring specific linguistic features (Flowerdew 2004; Ma 1993). The use of small specialised corpora instead of big generic corpora is well-established in discourse analysis because researchers find it easier to rely on a smaller number of whole texts with detailed metadata about speakers (McEnery et al. 2006).

Another advantage of corpus linguistics connected with objectivity is the necessity to thoroughly consider three main principles of corpus building: sampling, balancing and representativeness of the texts (Nelson, 2010: 56; McEnery et al. 2006: 13-21). Balancing and representativeness are of special importance to smaller specialised corpora such as the discussed corpus. The criterion of representativeness of a corpus is normally judged against the situational context and the linguistic context (Koester 2010: 69-71). The situational variability and representativeness of this specialised corpus are clearly determined by the focus on court cases with litigants in person who come from different social and educational backgrounds and opt for self-representation for different reasons. The corpus includes cases with well-educated and highly articulate litigants (i.e. David Irving and James Traficant used court as a forum for expressing their views despite having financial means for legal presentation); activists (i.e. Helen Steel and David Morris who chose to represent themselves because of their strong belief in the freedom of speech); and ordinary litigants in person who chose to represent themselves in typical small claims cases because of a lack of financial means. The representativeness of the linguistic context is ensured by the fact that all subcorpora include court hearings from the very beginning until the end and are thus representative of the evidentiary dialogic stages (witness examination) and monologic stages (opening and closing speeches) as well as procedural stages (discussions between the parties and the judge about order of witnesses, legal arguments, admissibility of evidence, etc). Since the differences between the paradigmatic and the narrative modes are of a universal character (Heffer 2005), litigants in person across different jurisdictions can be expected to have similar problems with communication in court. 
The principles of sampling and balancing are interconnected as both refer to choosing appropriate texts which represent a wide range of typical situations (McEnery 2006: 125). The sampling of the corpus was largely determined by the availability of courtroom materials and the motivation to include whole cases from different jurisdictions. The importance of including whole texts for the contextually-informed analysis when it is necessary to examine linguistic features within the text is supported by Flowerdew (2004: 15). The opportunity to compare how judges deal with the needs of litigants in person in different jurisdictions is especially valuable for legal professionals, stakeholders and practitioners as each jurisdiction uses a slightly different approach and the results are visible in interaction between litigants in person and judges. For now, the corpus is limited to only a few cases from several jurisdictions and thus cannot fully function for the needs of comparative legal studies. This use can be further explored in future.

Balancing the corpus as such remains a weakness because of the differences in sizes of individual cases and the variety of cases. But the corpus is a starting point for the project in progress and this weakness is counterbalanced by the fact that it is possible to search individual sub-corpora or combinations of them and thus control the input data. Since there is no objective or unified method to measure the representativeness of the corpus, it is the research question that determines the criteria for corpus building, balancing, sampling and representativeness (McEnery 2006: 21). The design of the corpus was thus adjusted to enable the answering of research questions from both disciplines, i.e. linguistics and socio-legal studies.

When designing the corpus the main challenge proved to be dealing with dialogic materials as it was necessary to divide the utterances in the transcripts into individual sentences according to the punctuation (sentence was defined as a sequence of words staring with a capital letter and ending with a full stop for simplification purposes). The choice of a sentence as a unit of analysis was guided by the need for an interdisciplinary and varied approach to data: research questions the corpus needed to answer were on the syntactical level. With the transcripts divided into sentences, it is easier to organise data, assign speakers to utterances, categorise types of utterances, categorise types of questions during witness examination, assign pragmatic marks ups, etc. Such basic division into sentences is problematic from the linguistic point of view as it does not account for discourse units. Pragmatic annotation would have been more functional if the corpus was designed for purely linguistic purposes. But the corpus would then not be easily applicable for answering research questions for socio-legal studies, where a fully automated annotation is an advantage for working with many varied cases. A basic simplified division proved to be more flexible for the reusability of the corpus.

Each sentence was marked up with four categories ('type', 'category', 'speaker', 'comment') for a combination of automatic and manual tagging. The outlay and regular punctuation of verbatim transcripts with exact indication of speakers allowed for speakers and categories to be assigned automatically to each sentence. Speakers were tagged as 'witness', 'judge', 'counsel' or 'litigant in person'. The division into categories according to types of utterances ('q' for questions, 'a' for answers and 'o' for other types of utterances) was a key step which 
helped distinguish between witness examination stages and procedural stages. This, for instance, allows the analyst to see how litigants in person negotiate their institutionally ambiguous role when examining other lay people (i.e. witnesses) and when discussing legal points and procedural matters with the judge and the opposing counsel. The mark-up category 'type' was reserved for types of questions and was tagged manually in a selected sub-corpus of cross-examination (described in Tkačuková 2010); the 'comment' mark up space was used for additional tags for pragmatic and semantic strategies and allows for a flexible manual tagging system which could fit the aims of potential future studies:

$<$ s comment="" speaker="counsel" category="question" type=""> Ms. Bobby, when you testified last week, do you recall a series of questions and answers that were asked to you about the relationship between Charles O'Nesti and Congressman Traficant? $</ \mathrm{s}><\mathrm{s}$ comment="" speaker="Smith" category="question" type=""> You recall that series of questions and answers? </s>A. <s comment="" speaker="witness" category="a" > Yes. </s>

The marked up documents were then tagged for parts of speech using TreeTagger (Schmid 1994) and uploaded into the corpus query system Sketch Engine (Kilgarriff 2014). As a result, the corpus and sub-corpora are now searchable according to different combinations of the following features: speakers, types of interaction, lemmas, words, phrases and making attribute-value queries specific for the Sketch Engine. The corpus required an individual approach to corpus building and a specific annotation system. But once designed it functions as a fully reusable source of information for an interdisciplinary analysis fulfilling the requirements of both disciplinary bases (i.e. linguistics and legal studies). The main advantage of the corpus is that it can be re-applied to answer research questions not originally envisaged (McEnery 2006: 30).

\section{Discourse marker 'well' in legal-lay discourse}

As mentioned in section 2, the focus of the article is on the roles of judges during procedural stages as evidenced through their use of 'well'-initiated turns. TkačukováTable 2 provides a general overview of the occurrences of 'well' in the turn-initial position according to the roles of speakers and all court hearing stages:

Table 2: Normalised frequency of the discourse marker 'well' in turn-initial position (normalised per million).

\begin{tabular}{|l|c|c|c|c|}
\hline & $\begin{array}{c}\text { McDonalds } \\
\text { sub-corpus } \\
\text { (per million) }\end{array}$ & $\begin{array}{c}\text { Irving sub-corpus } \\
\text { (per million) }\end{array}$ & $\begin{array}{c}\text { Traficant } \\
\text { sub-corpus } \\
\text { (per million) }\end{array}$ & $\begin{array}{c}\text { Small claims } \\
\text { sub-corpora } \\
\text { (per million) }\end{array}$ \\
\hline $\begin{array}{l}\text { Witnesses - under } \\
\text { witness examination } \\
\text { ('well' in second } \\
\text { turns) }\end{array}$ & 411.1 & 464.1 & 550.4 & 61.4 \\
\hline $\begin{array}{l}\text { LiPs - conducting } \\
\text { witness examination }\end{array}$ & 32.1 & 104.4 & 151.7 & 49.8 \\
\hline
\end{tabular}




\begin{tabular}{|l|c|c|c|c|}
\hline ('well' in first turns) & & & & \\
\hline $\begin{array}{l}\text { LiPs - procedural } \\
\text { discussions }\end{array}$ & 40.8 & 46.9 & 96.8 & 12.7 \\
\hline LiPs in total & 72.8 & 151.3 & 248.5 & 62.5 \\
\hline $\begin{array}{l}\text { Counsel - } \\
\text { conducting witness } \\
\text { examination } \\
\text { ('well' in first turns) }\end{array}$ & 12.8 & 83.1 & 54.2 & 18.4 \\
\hline $\begin{array}{l}\text { Counsel - } \\
\text { procedural } \\
\text { discussions }\end{array}$ & 7.3 & 22.0 & 13.7 & 3.1 \\
\hline Counsel in total & 20.1 & 105.0 & 67.9 & 21.5 \\
\hline $\begin{array}{l}\text { Judges - additional } \\
\text { questions for } \\
\text { witnesses } \\
\text { ('well' in first turns) }\end{array}$ & 14.1 & 62.3 & 122.8 & 9.4 \\
\hline $\begin{array}{l}\text { Judges - procedural } \\
\text { discussions }\end{array}$ & 60.3 & 139.5 & 331.5 & 20.7 \\
\hline Judges in total & 74.4 & 201.8 & 459.4 & 30.1 \\
\hline
\end{tabular}

The figures show that during witness examination 'well' is most frequently used by witnesses to initiate their second turns. In the first part of adjacency pairs, i.e. questioning turns, litigants in person use 'well' most frequently. Counsels use 'well' at least twice less than litigants in person. This could indicate that lay participants, witnesses and litigants in person, use 'well' most frequently because they are phrasing their narratives in the narrative mode. The paradigmatic mode of counsels' turns is more structured and does not require much selfcorrection, delays or rephrasing. Counsels mainly use 'well' to reinforce the challenging force of their cross-examining questions (Tkačuková 2010). The figures are comparable to those presented by Innes (2010), who provides a detailed overview of the functions, uses and frequencies of the discourse marker 'well' used by counsel and witnesses (i.e. uses of 'well' in its first turn and second turn positions). The findings in Innes (2010: 104) show that in its first turn position, 'well' is used mainly to challenge the witness, whereas in its second position 'well' introduces a delay tactic or justification/explanation.

Although 'well' is much more frequently used by witnesses, litigant in person and counsels during witness examination, the situation is different during procedural discussions. The shaded rows in Table 2 illustrate that during procedural stages judges use 'well' in the turninitial position approximately twice more than litigants in person and at least three times more than counsels. This is consistent with the fact that judges are the main contributors in the procedural and organisational stage of hearings and both parties turn to them for making decisions and litigants in person in particular expect their guidance and suggestions. The focus on judges' 'well'-initiated turns during procedural discussions illustrates additional roles judges have to undertake in cases with litigants in person.

The Sketch Engine offers a function for identifying collocations by setting the range of words preceding and/or following the word in question, the number of minimal occurrences of the 
collocation in the corpus and in the given range. The collocations are then listed according to different association scores. For the purposes of this study the following three scores are of special importance: MI score, T-score and logDice score. The first two are common association scores. The MI score is not dependent on the size of the corpus and identifies lexical bundles and idiomatic occurrences, whereas the T-score is corpus-specific and bears more information about the grammatical use of the word. The logDice score is a modification of the Dice score. The logDice is based on several measures: the frequency of the precise relation, the frequency of the headword in the same syntactic position with any collocation and the frequencies of the collocation in any syntactic position (Rychly 2008). This was thus found to be the most reliable score for small specialised corpora such as the present corpus because it combines grammatical and lexical criteria.

A combination of these scores was used to identify the left-hand and right-hand context of the discourse marker 'well' in turn-initial positions as used by judges. Punctuation marks (full stop, dashes and question marks) rank highest by all three association measures for the lefthand context (L4-L1) in the data. Table 3 shows the top three results are ranked according to the $\log$ Dice score:

Table 3: Association measures for left-hand context of 'well'-initiated turns used by judges ranked according to the logDice score.

\begin{tabular}{|c|c|c|c|c|}
\hline & Freq & T-score & MI & logDice \\
\hline$\cdot$ & 562 & 16.999 & 3.73 & 4.71 \\
\hline$?$ & 175 & 7.078 & 3.207 & 4.182 \\
\hline----- & 126 & 6.069 & 6.016 & 6.92 \\
\hline
\end{tabular}

As established in section 2, court transcribers use a varied number of dashes to indicate interruptions in verbatim transcripts and their occurrence preceding 'well'-initiated turns signifies the use of 'well' for taking the floor and interrupting the previous speaker. The occurrence of the question mark then mainly applies to instances of judges interjecting witness examination in order to inquire about its course or ask specifying questions. Table 4 shows the proportion of 'well'-initiated interjections and interruptions by judges. The first two rows show judges' 'well'-initiated interjections of Q/A sequences during witness examination, whereas the last two rows show the rate of judges' 'well'-initiated mid-turn interruptions during procedural discussions.

Table 4: The proportion of 'well'-initiated interjections and interruptions by judges (LiPs stands for litigants in person).

\begin{tabular}{|l|c|c|c|c|}
\hline & $\begin{array}{c}\text { McDonalds } \\
\text { sub-corpus }\end{array}$ & $\begin{array}{c}\text { Irving sub- } \\
\text { corpus }\end{array}$ & $\begin{array}{c}\text { Traficant } \\
\text { sub-corpus }\end{array}$ & $\begin{array}{c}\text { Small claims } \\
\text { sub-corpus }\end{array}$ \\
\hline $\begin{array}{l}\text { Judges interjecting LiPs' } \\
\text { witness examination }\end{array}$ & $87.8 \%$ & $79.9 \%$ & $67.3 \%$ & $89.9 \%$ \\
\hline $\begin{array}{l}\text { Judges interjecting counsels' } \\
\text { witness examination }\end{array}$ & $12.2 \%$ & $20.01 \%$ & $32.7 \%$ & $10.1 \%$ \\
\hline
\end{tabular}




\begin{tabular}{|l|c|c|c|c|}
\hline $\begin{array}{l}\text { Judges' mid-turn } \\
\text { interruptions of LiPs in } \\
\text { procedural stages }\end{array}$ & $59.5 \%$ & $63.7 \%$ & $58.9 \%$ & $78.3 \%$ \\
\hline $\begin{array}{l}\text { Judges' mid-turn } \\
\text { interruptions of counsels in } \\
\text { procedural stages }\end{array}$ & $40.5 \%$ & $36.3 \%$ & $41.1 \%$ & $21.7 \%$ \\
\hline
\end{tabular}

Judges interrupt litigants in person and counsels in similar proportions during procedural discussions. But the rate of judges interjecting litigants in person's witness examination is much higher across all the cases. This may be due to the fact that judges need to complement the litigants in persons' witness examination by asking witnesses additional questions. Another reason for judges to interrupt litigants' in person witness examination is to control its course by pointing out relevant aspects to their decision-making and ensuring court time is used more efficiently, as illustrated in Example 1:

Example 1 (Irving Sub-Corpus 2): The judge interferes with the litigant in person's (Irving's) cross-examination of a witness.

MR IRVING: I am dangerous to the whole of existing history of the Holocaust? Is that what is implied by that?

MR JUSTICE GRAY: Well, that is, in the end, a matter for me, what Professor Lipstadt would have been understood to mean, but it seems to me it is pretty clear that the danger is that a lot of people will -- I was going to use the word "swallow", that is a bit offensive -accept the denial case.

In example 1, the judge interferes with Mr Irving's cross-examination by saying clearly which aspects are to be left to him. By doing so, the judge reinforces his authority implying that it is ultimately his decision. The discourse marker projects the judge's stance to the line of questioning chosen by the litigant in person and the redundancy and limited value of Irving's cross-examination questions to his decision making. Reinforcing their role as decision-makers is the predominant function judges employ in 'well'-initiated interruptions of counsels as shown in Example 2:

Example 2 (McDonalds Sub-Corpus 1): Judge's mid-turn interruption of the counsel during procedural discussions.

MR. RAMPTON : With respect, I do not accept that. I will dutifully -----

MR. JUSTICE BELL: Well, that is my ruling.

MR. RAMPTON: If that is your Lordship 's ruling, I dutifully obey.

The judge interrupts counsel to briefly state that there is no point in objecting to his ruling and 'well' helps indicate the force of the proposition expressed by the judge, which counsel accepts as an irreversible position. Projecting their firm stance and re-enforcing their authority is the main function of judges' 'well' initiated mid-turn interruptions: they amount to almost $70 \%$ of all their 'well'-initiated mid-turn interruptions directed at counsel. When directing their speech to litigants in person judges follow further objectives; judges need to 
ensure that there are no misunderstandings and that hearings are not strongly impeded by the lay people's lack of legal knowledge, experience or training.

While the left-hand context of 'well' illustrates when judges take the floor and how they control the flow of interaction, the right-hand context (R1-R5) helps identify different functions of judge's 'well'-initiated turns. The results in Table 5 are ranked according to the $\log$ Dice score:

Table 5: Association measures for right-hand context of 'well'-initiated turns used by judges ranked according to the $\log$ Dice score.

\begin{tabular}{|l|l|l|l|l|l|l|l|l|l|}
\hline & Freq & $\begin{array}{l}\text { T- } \\
\text { score }\end{array}$ & MI & logDice & & Freq & $\begin{array}{l}\text { T- } \\
\text { score }\end{array}$ & MI & logDice \\
\hline n't & 326 & 7.389 & $\begin{array}{l}4.21 \\
1\end{array}$ & 7.587 & be & 303 & 3.66 & 3.555 & 4.503 \\
\hline may & 50 & 4.275 & $\begin{array}{l}4.50 \\
1\end{array}$ & 5.431 & know & 46 & 3.651 & 3.521 & 4.47 \\
\hline think & 78 & 5.371 & $\begin{array}{l}4.30 \\
9\end{array}$ & 5.262 & what & 56 & 4.64 & 3.473 & 4.436 \\
\hline , & 1004 & 21.215 & $\begin{array}{l}4.23 \\
5\end{array}$ & 5.215 & could & 32 & 3.508 & 3.408 & 4.358 \\
\hline will & 63 & 4.726 & $\begin{array}{l}4.19 \\
1\end{array}$ & 5.139 & not & 170 & 7.525 & 3.313 & 4.289 \\
\hline put & 29 & 2.977 & $\begin{array}{l}4.08 \\
9\end{array}$ & 4.994 & it & 177 & 7.873 & 3.282 & 4.258 \\
\hline I & 369 & 12.152 & $\begin{array}{l}3.93 \\
9\end{array}$ & 4.917 & just & 32 & 3.079 & 3.17 & 4.118 \\
\hline do & 154 & 6.158 & $\begin{array}{l}3.80 \\
2\end{array}$ & 4.769 & if & 48 & 3.75 & 3.107 & 4.067 \\
\hline we & 98 & 5.704 & $\begin{array}{l}3.74 \\
3\end{array}$ & 4.709 & have & 91 & 5.604 & 3.002 & 3.976 \\
\hline can & 51 & 4.533 & $\begin{array}{l}3.74 \\
3\end{array}$ & 4.699 & you & 131 & 6.828 & 2.991 & 3.967 \\
\hline there & 70 & 5.042 & $\begin{array}{l}3.65 \\
4\end{array}$ & 4.617 & would & 35 & 2.414 & 1.877 & 2.844 \\
\hline
\end{tabular}

The top collocations for the right-hand context with the highest logDice score and association scores include the following words: pronouns 'I', 'we', 'you'; verbs 'think', 'know', 'have'; conjunction 'if'; negation form 'not', 'n't'; modal verbs 'can', 'could', 'may', 'would'. The frequent occurrence and close association of these words with 'well' coincide with different functions of the discourse marker: explanation ('think', 'know', 'have'), instructions ('have', 'you'), suggestions (modal verbs, 'if'), mitigation ('we', modal verbs, 'think'), disagreement (forms of negation).

To meet the needs of the interdisciplinary topic, the examples were further classified on two levels. The overarching categorisation is according to institutional functions that judges perform through 'well'-initiated turns. Subordinate to it is the categorisation according to 
linguistic functions of 'well'. The first tier of categorisation is thus guided by the roles of judges according to the civil procedure rules for legal proceedings with an unrepresented party (Trinder et al. 2014; Zuckerman 2014). The second tier of categorisation is adapted from the linguistic research by Innes (2010), Lam (2010) and Fuller (2003): textual function of introducing the topic; textual function of linking and establishing coherence; responsive interpersonal function of insufficiency/incompleteness; emotive interpersonal function of challenge/dismissal/state of mind; interactional function of reformulation; interactional function of turn-management; and pragmatic function of threat mitigation. The two-tier classification meets the needs of both disciplinary bases (i.e. linguistics and legal studies). Table 6 shows the overlaps between the legal and linguistic categorisations. There are often several linguistic functions corresponding to a single legal function of 'well'-initiated turns used by judges. Examples below illustrate one linguistic function from each legal category.

Table 6: Legal and linguistic classification of 'well'-initiated turns as used by judges during interaction with litigants in person (LiP).

\begin{tabular}{|c|c|c|c|}
\hline \multicolumn{4}{|c|}{$\begin{array}{l}\text { Legal function: Providing advice/guidance/explanation on legal points/concepts } \\
\text { Linguistic functions: } \\
\text { - } \quad \text { Textual function of introducing the topic } \\
\text { - } \quad \text { Textual function of linking and establishing coherence } \\
\text { - } \quad \text { Responsive interpersonal function of insufficiency/incompleteness }\end{array}$} \\
\hline McDonalds sub-corpus & Irving sub-corpus & Traficant sub-corpus & \\
\hline & & & \\
\hline \multicolumn{4}{|c|}{$\begin{array}{l}\text { Example } 3 \text { (Small Claims Sub-Corpus 2): } \\
\text { - Textual function of linking and establishing coherence } \\
\text { LiP: In regards to opening statement, that is my opening statement and I can say and present } \\
\text { my case in a manner that would ---- } \\
\text { THE COURT: Well, opening statement is just what it says. It's a statement of your position } \\
\text { as far as what your case is about or what you contend your case is about. Some people say } \\
\text { it's like a road map of their case. You cannot testify during it, and you cannot make } \\
\text { arguments. There is a difference between an opening statement and a closing argument. So } \\
\text { you cannot make an argument, but you can lay out the facts as you allege the facts to be. }\end{array}$} \\
\hline \multicolumn{4}{|c|}{$\begin{array}{l}\text { Legal function: Providing advice/guidance/explanation on procedural matters } \\
\text { Linguistic functions: } \\
\text { - } \quad \text { Textual function of introducing the topic } \\
\text { - } \quad \text { Textual function of linking and establishing coherence } \\
\text { - } \quad \text { Responsive interpersonal function of insufficiency/incompleteness } \\
\end{array}$} \\
\hline McDonalds sub-corpus & Irving sub-corpus & Traficant sub-corpus & \\
\hline $37.2 \%$ & & & \\
\hline \multicolumn{4}{|c|}{$\begin{array}{l}\text { Example } 4 \text { (Traficant Sub-Corpus): } \\
\text { - Responsive interpersonal function of insufficiency/incompleteness } \\
\text { MR. TRAFICANT: The tape recording of the dying man who they were able to tape but not } \\
\text { make available for me to tape and depose. } \\
\text { THE COURT: Well, the way you're putting it has not in itself been presented to me, but we } \\
\text { have not ruled that -- I have a conditional ruling on evidence that is conditioned on the } \\
\text { Government being able to demonstrate certain things that the law requires them to }\end{array}$} \\
\hline
\end{tabular}


demonstrate under these circumstances. It was a pretty straight forward ruling, and you'll see it when you go back on the docket.

Legal function: Giving instructions/suggestions as to (in)appropriateness and (in)effectiveness

\section{Linguistic functions:}

- Textual function of introducing the topic

- Responsive interpersonal function of insufficiency/incompleteness

- Interactional function of turn-management

\begin{tabular}{|c|c|c|c|}
\hline McDonalds sub-corpus & Irving sub-corpus & Traficant sub-corpus & $\begin{array}{l}\text { Small claims sub- } \\
\text { corpus }\end{array}$ \\
\hline $24.9 \%$ & $21.2 \%$ & $13.2 \%$ & $28.9 \%$ \\
\hline
\end{tabular}

Example 5 (McDonalds Sub-Corpus):

- Interactional function of turn-management

MS. STEEL: I do not think it should necessarily be assumed that he was from America. He could be from -----

MR. JUSTICE BELL: Well, ask about that if you like. I do not want to interrupt your crossexamination, but one thing you might ask is where Mr. Copeland arrived from, to the best of Mr. Mehigan's knowledge.

Example 6 (Irving Sub-Corpus):

- Textual function of introducing the topic

MR IRVING: It is the way Morland J would put it probably too.

MR JUSTICE GRAY: Well, you might then take the opportunity, either in cross-

examination or perhaps re-examining yourself, to make the points you are wanting to make in reference to Professor Levin or Dr Levin's report.

\section{Legal function: Give rulings, reinforcing authority \\ Linguistic functions:}

- Responsive interpersonal function of insufficiency/incompleteness

- Emotive interpersonal function of challenge/dismissal/state of mind

- Pragmatic function of threat mitigation

\begin{tabular}{|c|c|c|c|}
\hline McDonalds sub-corpus & Irving sub-corpus & Traficant sub-corpus & $\begin{array}{l}\text { Small claims sub- } \\
\text { corpus }\end{array}$ \\
\hline $4.6 \%$ & $8.9 \%$ & $14.6 \%$ & $3.5 \%$ \\
\hline
\end{tabular}

Example 7 (Small Claims Sub-Corpus 4):

- $\quad$ Emotive interpersonal function of challenge/dismissal/state of mind

MR. C.: Okay. But he did answer it.

THE COURT: Well, the legal effect of that, I will sort out.

MR. C.: Okay.

THE COURT: He said what he said.

\section{Legal function: Mitigating, resolving issues between parties}

Linguistic functions:

- Pragmatic function of threat mitigation

\begin{tabular}{|c|c|c|c|}
\hline McDonalds sub-corpus & Irving sub-corpus & Traficant sub-corpus & $\begin{array}{l}\text { Small claims sub- } \\
\text { corpus }\end{array}$ \\
\hline $7.8 \%$ & $13.2 \%$ & $6.8 \%$ & $11.3 \%$ \\
\hline
\end{tabular}

Example 8 (McDonalds Sub-Corpus):

RAMPTON: It is sometimes necessary to say things rather than often necessary to say things which may be provocative but which nevertheless it is necessary to say.

MR. JUSTICE BELL: Well, we have been in this courtroom a long time together, we are going to be here for many months more, and anything which those conducting the case, 
either counsel or the Defendants themselves, can do to keep the temperature at a steady level showing some mutual respect and courtesy is to be welcomed by me.

Legal function: Challenging, expressing disagreement with the proposition expressed by LiPs

\section{Linguistic functions:}

- Responsive interpersonal function of insufficiency/incompleteness

- Emotive interpersonal function of challenge/dismissal/state of mind

\begin{tabular}{|c|c|c|c|}
\hline McDonalds sub-corpus & Irving sub-corpus & Traficant sub-corpus & $\begin{array}{l}\text { Small claims sub- } \\
\text { corpus }\end{array}$ \\
\hline $9.7 \%$ & $19.3 \%$ & $16.4 \%$ & $10.1 \%$ \\
\hline
\end{tabular}

Example 9 (Irving Sub-Corpus):

- $\quad$ Emotive interpersonal function of challenge/dismissal/state of mind

Mr Irving: Yes, but the left wing -

MR JUSTICE GRAY: Well, do not argue about it, we have the evidence.

\section{Legal function: Other}

\section{Linguistic functions:}

- Textual function of introducing the topic

- Textual function of linking and establishing coherence

- Interactional function of reformulation

- Interactional function of turn-management

\begin{tabular}{|l|c|c|c|}
\hline McDonalds sub-corpus & Irving sub-corpus & Traficant sub-corpus & $\begin{array}{l}\text { Small claims sub- } \\
\text { corpus }\end{array}$ \\
\hline $4.4 \%$ & $4.8 \%$ & $10.6 \%$ & $10.5 \%$ \\
\hline
\end{tabular}

Example 10 (Small Claims Sub-Corpus 4):

MR. C.: Well, now, who is on first?

THE COURT: Well, Mr. W. is going to call Mr. P., and then you will cross-examine him.

The above examples show that although 'well' could be omitted, it is significant for defining the force of the propositions expressed. In Examples 3 and 4, the discourse marker introduces the judges' explanation of legal concepts or procedural matters. In addition to introducing the explanation of the concept of 'opening statement' in Example 3, the discourse marker 'well' performs the textual function of establishing coherence. In Example 4, the discourse marker directs towards the insufficiency of the litigant in person's previous turn. What both examples have in common is the need to clarify a complex issue for litigants in person. The judges should thus preferably formulate their explanation in the narrative mode (e.g. comparing opening statements to road maps in Example 3). Both examples, however, contain lexical and syntactic patterns of the professional paradigmatic mode (e.g. 'layout the facts as you allege the facts to be', 'conditional ruling on evidence that is conditioned on the Government being able to demonstrate'). Authentic samples from courtroom interactions extracted from corpora can be used for the purposes of training judges to illustrate how they can explain common concepts or procedures to lay people. Since the second category of providing guidance on procedural matters is the most frequently employed function of 'well' initiated turns, it is important for judges to ensure their explanation of procedures can be easily understood by litigants in person. 
In Example 5 the discourse marker 'well' is followed by an imperative and in Example 6 by the modal verb 'might'. Both judges introduce suggestions as to preferable and more effective options litigants in person might want to take. In Example 5, this is further reinforced by the turn-managing function of 'well'. Similarly, Example 6 illustrates 'well' in its textual function of introducing the topic. Examples 7, 8 and 9 illustrate that amongst the multiple judges' roles are ascertaining their authority through making firm decisions (Examples 7 and 9) but also through being mitigators between the parties (Example 8). Example 10 shows one of legally unspecific uses 'well', to which only linguistic functions were assigned.

The analysis only relates to 'well'-initiated turns used by judges. But by combining linguistic and legal approaches, Table 6 gives an indication of what roles are most common for judges in cases with litigants in person and how they engage with litigants in person. The results show that (i) providing guidance on procedural matters and (ii) giving suggestions as to (in)effectiveness of arguments or undertakings are the most frequent roles of judges in cases with litigants in person. This resonates with the findings by Trinder et al (2014). For the purposes of training the judiciary, samples of real-life interaction from court can serve as useful examples to discuss and learn from.

\section{Conclusions}

Procedural stages are important for negotiating meaning and institutional roles through legallay communication. Judges' 'well'-initiated turns show that judges often reinforce their authority when directing their speech to counsel and provide explanation or advice when talking to litigants in person. The most frequent roles judges undertake through 'well'prefaced turns is providing explanation on procedural matters and legal concepts as well as initiating face threat mitigation.

By illustrating the uses of 'well' and functions of judges' 'well'-initiated turns during procedural discussions, the article shows how a corpus linguistics approach can help to trace specific linguistic features to uncover more general aspects useful for other disciplines (e.g. legal studies). If the interdisciplinary approach is taken into account from the very beginning of the process of corpus building, the corpus can be re-used for purposes not originally envisioned. The presented corpus has potential for being constantly supplemented and further exploited for developing materials for the judiciary or for developing practical handbookstyle information packages for litigants in person.

A similar approach shown here can be used to analyse how the meaning of common legal concepts (e.g. 'evidence', 'opening speech', ‘cross-examination') is negotiated and explained to litigants in person in practice. Although many judges have personal experience with litigants in person struggling with these concepts (Trinder et al 2014), samples from court interaction can help judges practice clearer explanation strategies. This would give specific initiatives for the training of the judiciary but also inform personal support units and first tier support organisation (e.g. Personal Support Units) on what aspects to base their guidance materials and how to help litigants in person. 
A corpus approach provides a firm methodological basis for socio-legal studies as it presents an opportunity to work with real-life interactions. Corpora can be used as a complementary methodological tool in addition to empirical research methods, questionnaires, interviews and other socio-legal research methods.

\section{Bibliography}

Aldridge, M. and Luchjenbroers, J. 2007. 'Linguistic Manipulation in Legal Discourse: Framing Questions and “Smuggling” Information', International Journal of Speech, Language and the Law 14(1), pp 85-107.

Atkinson, J. M. and Drew, P. 1979. Order in Court: The Organisation of Verbal Interaction in Judicial Settings. London: Macmillan.

Carranza, I. E. 2004. 'Discourse markers in the construction of the text, the activity, and the social relations'. Current Trends in the Pragmatics of Spanish 123, pp 203-227.

Carter, R. and McCarthy, M. 2006. Cambridge grammar of English: a comprehensive guide; spoken and written English grammar and usage. Cambridge: CUP.

Conley, J.M. and O’Barr, W.M. 1998. Just Words: Law, Language, and Power, Chicago: University of Chicago.

Cotterill, J. 2003. Language and Power in Court: A Linguistic Analysis of the O.J. Simpson Trial. Basingstoke: Palgrave Macmillan.

Cuenca, M. J. 2008. 'Pragmatic markers in contrast: The case of well'. Journal of Pragmatics (408), pp1373-1391.

Danet, B., et al. 1980. 'An Ethnography of Questioning in the Courtroom' in R.W. Shuy and A. Shnukal (eds.) Language Use and the Uses of Language. Washington, D.C.: Georgetown University Press.

Drew, P. 1990. 'Strategies in the Contest between Lawyer and Witness in CrossExamination' in J.N. Levi and A.G. Walker (eds.) Language in the Judicial Process, New York and London: Plenum Press.

Eades, D. 1996. 'Verbatim Courtroom Transcripts and Discourse Analysis', in H. Kniffka (ed.) Recent Developments in Forensic Linguistics. Frankfurt am Main: Peter Lang.

Flowerdew, L. (2004). 'The argument for using English specialized corpora to understand academic and professional language' in U. Connor and T. Upton (eds.) Discourse in the professions: Perspectives from corpus linguistics, Amsterdam: John Benjamins, pp 11-33.

Fraser, B. 1993. 'Discourse markers across language' in L. Bouton and Y Kachru (eds.) Pragmatics and Language Learning, vol. 4, pp 3-16. Urbana-Champaign: IL: University of Illinois Press. 
Fraser, H. 2003. 'Issues in Transcription: Factors Affecting the Reliability of Transcripts as Evidence in Legal Cases', Forensic Linguistics 10 (2), pp 203-226.

Fuller, J. M. 2003. 'The influence of speaker roles on discourse marker use'. Journal of Pragmatics 35(1), pp 23-45.

Gibbons, J. 2003. Forensic Linguistics: An Introduction to Language in the Justice System. Malden, MA and Oxford: Blackwell.

Hale, S. 1999. 'Interpreters' Treatment of Discourse Markers in Courtroom Questions', Forensic Linguistics 6(1), pp 57-82.

Harris, S. 1984. 'Questions as a Mode of Control in Magistrates' Courts', International Journal of the Sociology of Language, pp 49: 5-27.

Heffer, C. 2005. The Language of Jury Trial: A Corpus-Aided Analysis of Legal-Lay Discourse. Basingstoke: Palgrave Macmillan.

Heffer, C. et al. 2013. Legal-Lay Communication: Textual Travels in the Law. Oxford: OUP. Innes, B. 2010. "“Well, that's why I asked the question sir": Well as a discourse marker in court'. Language in Society 39 (1), pp 95-117.

Jackson, C., and Jones, D. 2013. 'Well they had a couple of bats to be truthful: Wellprefaced, self-initiated repairs in managing relevant accuracy in interaction'. Journal of Pragmatics 47(1), pp 28-40.

Jucker, Andreas H. 1993. 'The discourse marker well: a relevance theoretical account'. Journal of Pragmatics 19(5), pp 435-452.

Koester, A. 2010. 'Building Small Specialised Corpora' in O'Keeffe, A and M. McCarthy (eds.), pp 66-79. The Routledge Handbook of Corpus Linguistics. London and New York: Routledge.

Kilgarriff, A. et al. 2014. 'The Sketch Engine: ten years on'. Lexicography 1 (1): pp 1-30.

Kim, H. R. S. 2013. 'Retroactive indexing of relevance: the use of well in third position'. Research on Language \& Social Interaction 46(2), pp 125-143.

Lam, P. W. 2010. 'Toward a functional framework for discourse particles: a comparison of well and so'. Text \& Talk - An Interdisciplinary Journal of Language, Discourse \& Communication Studies 30 (6), pp 657-677.

Luchjenbroers, J. 1997. “"In your Own Words ..." Questions and Answers in a Supreme Court Trial', Journal of Pragmatics 27, pp 477-503.

Ma, B. K. C. 1993. 'Small-corpora concordancing in ESL teaching and learning'. Hong Kong Papers in Linguistics and Language Teaching 6: pp 11-30. 
Matoesian, G. 2005. 'Nailing down an Answer: Participations of Power in Trial Talk', Discourse Studies 7 (6), pp 733-759.

McEnery, T., Xiao, R. and Y. Tono. 2006. Corpus-Based Language Studies. London: Routledge.

McEnery, T., and A. Wilson. 2001. Corpus Linguistics. Edinburgh: Edinburgh University Press.

Nelson, M 2010. 'Building a Written Corpus: What are the Basics' in O'Keeffe, A and M. McCarthy (eds.), pp 53-65. The Routledge Handbook of Corpus Linguistics. London and New York: Routledge.

Norrick, N. 2001. 'Discourse markers in oral narrative', Journal of Pragmatics 33, pp 849878.

O'Barr W.M. and Conley, J.M. 1990. 'Litigant Satisfaction versus Legal Adequacy in Small Claims Court Narratives' in J.N. Levi and A.G. Walker (eds.) Language in the Judicial Process. New York and London: Plenum.

Philips, S.U. 1987. 'On the Use of WH Questions in American Courtroom Discourse: A Study of the Relation between Language Form and Language Function' in L. Kedar et al. (eds.) Power through Discourse, Norwood: Ablex.

Rühlemann, C. 2010. 'What can a Corpus Tell us about Pragmatics?' in O'Keeffe, A and M. McCarthy (eds.) The Routledge Handbook of Corpus Linguistics, pp 288-301. London and New York: Routledge.

Rychlý, P. 2008. 'A lexicographer-friendly association score'. Proceedings of Recent Advances in Slavonic Natural Language Processing, RASLAN, pp 6-9.

Schiffrin, D. 1987. Discourse markers. London: CUP.

Schmid, H. 1994. 'Probabilistic Part-of-Speech Tagging Using Decision Trees'. Proceedings of International Conference on New Methods in Language Processing, Manchester, UK. 19 January 2015 <ftp://ftp.ims.uni-stuttgart.de/pub/corpora/tree-tagger1.pdf>

Schourup, L. 1999. 'Discourse markers: Tutorial overview'. Lingua 107, pp 227-265.

Svartvik, J. 1980. 'Well in conversation'. Studies in English Linguistics for Randolph Quirk, 5, pp 167-177.

Thornbury, S. 2010. 'What can a Corpus Tell us about Discourse?' in O'Keeffe, A and M. McCarthy (eds.) The Routledge Handbook of Corpus Linguistics, pp 270-287. London and New York: Routledge.

Tkačuková, T. 2010. 'Cross-Examination Questioning: Lay People as Cross-Examiners' in M. Coulthard and A. Johnson (eds.). The Routledge Handbook of Forensic Linguistics. London and New York: Routledge. 
Tkačuková, T. 2011. 'Lay People as Cross-Examiners: A Linguistic Analysis of the Libel Case McDonald's Corporation v. Helen Steel and David Morris', The International Language of Speech, Language and the Law 17 (2), pp 307-310.

Tkachuk, T. 2008. 'Turn-Taking Management during Cross-Examination: Lay People as Cross-Examiners', pp 72-77. Topics in Linguistics: Politeness and Interaction. Nitra: Constantine the Philosopher University.

Tkachuk, T. 2007. 'Linguistic Analysis of Lay Advocacy: Do Lay People Stand a Chance when Representing themselves in Court?', Proceedings of the Second European IAFL Conference on Forensic Linguistics / Language and the Law, pp 239-247. Barcelona: University Pompeu Fabra.

Trinder. L. et al. 2014. Litigants in Person in Private Family Law Cases. Ministry of Justice Analytical Series. Accessed on 9/12/2014 <www.justice.gov.uk/publications/research-andanalysis/moj>.

Walker, A. G. 1990. 'Language at Work in the Law: The Customs, Conventions, and Appelate Consequences of Court Reporting' in J.N. Levi and A.G. Walker (eds.) Language in the Judicial Process. New York and London: Plenum Press.

Walker, A.G. 1986. 'The Verbatim Record: The Myth and the Reality' in S. Fisher and A.D. Todd (eds.) Discourse and Institutional Discourse, New Jersey: Ablex.

Woodbury, H. 1984. 'The Strategic Use of Questions in Court', Semiotica 48 (3/4), pp 197228.

Zuckerman, A. 2014. 'No Justice without Lawyers - The Myth of an inquisitorial Solution'. CJQ 33 (4), pp 355-374.

\section{Reports}

'The Judicial Working Group on Litigants in Person: Report' 2013. $1^{\text {st }}$ Sep 2014. Available from <http://www.judiciary.gov.uk/wpcontent/uploads/JCO/Documents/Reports/lip_2013.pdf > 